\title{
Diagnostic anoctamin-5 protein defect in patients with ANO5- mutated muscular dystrophy
}

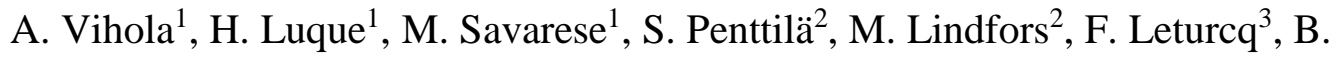

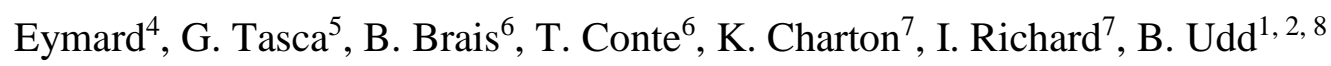

\author{
${ }^{1}$ Folkhälsan Institute of Genetics and Department of Medical Genetics, Medicum, \\ 00014 University of Helsinki, Finland \\ ${ }^{2}$ Neuromuscular Research Center, University and University Hospital of Tampere, \\ Finland \\ ${ }^{3}$ Laboratoire de génétique et biologie moléculaire, hôpital Cochin, AP-HP, université \\ Paris Descartes-Sorbonne Paris Cité, Paris, France \\ ${ }^{4}$ Institute of Myology, Pitié-Salpêtrière Hospital, Paris, France \\ ${ }^{5}$ Istituto di Neurologia, Università Cattolica del Sacro Cuore, Fondazione Policlinico \\ Universitario "A. Gemelli", Rome, Italy \\ ${ }^{6}$ Montreal Neurological Institute, McGill University, Montreal, Canada \\ ${ }^{7}$ INSERM U951, INTEGRARE Research Unit, and Généthon, Evry, France \\ ${ }^{8}$ Department of Neurology, Vaasa Central Hospital, Vaasa, Finland
}

\section{Corresponding author:}

Dr. Anna Vihola

email anna.vihola@helsinki.fi

Keywords: Limb-Girdle Muscular Dystrophy, LGMD2L, DMM3, ANO5

Running title: Diagnostic ANO5 western blotting

Word count: 1960

Number of figures: 2

Number of tables: 2

Supporting information: Supplemental figures 1-4 


\begin{abstract}
Aims: Previously, detection of ANO5 protein has been complicated by unspecific antibodies, most of which have not identified the correct protein. The aims of the study were to specify ANO5 protein expression in human skeletal muscle, and to investigate if the ANO5 protein levels are affected by different ANO5 mutations in anoctaminopathy patients.
\end{abstract}

Methods: Four different antibodies were tested for ANO5 specificity. A sample preparation method compatible with membrane proteins, combined with tissue fractionation was used to determine ANO5 expression in cell cultures expressing ANO5, in normal muscles and eight patient biopsies with six different ANO5 mutations in homozygous or compound heterozygous states, and in other dystrophies. Results: Only one specific monoclonal N-terminal ANO5 antibody was efficient in detecting the protein, showing that ANO5 is expressed as a single $107 \mathrm{kD}$ polypeptide in human skeletal muscle. The truncating mutations c.191dupA and c.1261C>T were found to abolish ANO5 expression, whereas the studied point mutations had variable effects, however, all the ANO5 mutations resulted in clearly reduced ANO5 expression in the patient muscle membrane fraction. Attempts to detect ANO5 using immunohistochemistry were not yet successful.

Conclusions: The data presented here indicate that the ANO5 protein expression is decreased in ANO5-mutated muscular dystrophy and that most of the non-truncating pathogenic ANO5 mutations likely destabilize the protein and cause its degradation. The method described here allows direct analysis of human ANO5 protein, which can be used in diagnostics, for evaluating the pathogenicity of the potentially harmful ANO5 variants of uncertain significance. 


\section{Introduction}

The limb-girdle muscular dystrophies (LGMDs) comprise a genetically complex group of muscular diseases affecting preferably proximal muscles [1]. The human ANO5 (TMEM16E) gene harbors $>70$ recessive mutations causing adult-onset muscle phenotypes such as limb-girdle muscular dystrophy type 2L (LGMD2L; OMIM 611307) and Miyoshi muscular dystrophy -like disease with distal phenotype (MMD3; OMIM 613319) [2-5].

Clinical features can vary from just high CK levels, mild weakness and exercise myalgia to more severe muscular atrophies. Weakness can be proximal, distal, or both in some cases $[3,4,6]$. Asymmetric muscle involvement and gender imbalance, men being more frequently and more severely affected, are features of anoctaminopathy. No clear genotype-phenotype correlation has been found $[3,6]$. Dominant mutations in ANO5 affecting the amino acid C356 cause a completely different phenotype: gnathodiaphyseal dysplasia (GDD; OMIM \#166260), a skeletal syndrome [7, 8].

The anoctamin/TMEM16 family of genes, ANO1 - ANO10, encodes for 10 eight-pass transmembrane proteins with diverse physiological functions, including $\mathrm{Ca}^{2+}$ activated $\mathrm{Cl}^{-}$channels, cation channels and lipid scramblases [9]. However, ANO5 does not show any of these activities $[10,11]$. A recent report on ANO5 deficient mouse model suggested that ANO5 has a role in muscle membrane repair and regeneration [12]. The human ANO5 gene is transcribed into one protein-coding mRNA species with 22 exons, giving rise to a 913 amino acid, $107 \mathrm{kD}$ ANO5 protein (TMEM16E) (Uniprot Q75V66-1). The functions of ANO5 are not fully clarified, although it may have a role in membrane dynamics [12]. 
A major restriction for ANO5 research involving human patients has been the lack of specific antibodies. Here we describe a western blotting method to study ANO5 protein expression in human muscle biopsies and subcellular fractions. The method described here enables analyzing the consequences of different ANO5 mutations at protein level. 


\section{Materials and Methods}

\section{Patients}

Biopsies were taken for diagnostic purpose and informed consent was obtained from all individual participants included in the study, according to the Declaration of Helsinki, and approved by the institutional review boards. Altogether eight anoctaminopathy patients (four Finnish, one French and three Italian), homozygous or compound heterozygous for pathogenic ANO5 mutations, were included (Table 1 and Supplemental Figure S1). One patient with undefined myopathy, heterozygous for one ANO5 anomaly at mRNA level, was used as a carrier control. In addition, 11 control individuals free of muscular disease were included (Table 2).

\section{Constructs}

The plasmid expression vector containing the wild-type full-length human ANO5 cDNA tagged with V5 epitope at its 3'end, hANO5wt-V5, has been described previously as hGDD1-V5 [8].

\section{Cell culture and transfection}

COS- 1 cells (ATCC, Manassas, VA, USA) were cultured at $+38^{\circ} \mathrm{C}, 5 \% \mathrm{CO}_{2}$, in DMEM supplemented with 10\% FCS, 1\% PenStrep and 1\% Glutamax. For transfection experiments, COS-1 cells were seeded on 6-well plates and grown to 60$70 \%$ confluence overnight. The next day, the cells were transfected with hANO5wtV5 using FuGene 6 (Promega, Madison, WI, USA), with DNA $(\mu \mathrm{g})$ :FuGene $6(\mu \mathrm{l})$ ratio 1:3. Two days after transfection the cells were harvested for western blotting. Untransfected COS-1 cells were used as negative control. 


\section{Subcellular protein fractionation}

Frozen muscle sections (40-60 x $12 \mu \mathrm{m})$ were placed in pre-chilled microcentrifuge tubes, and ProteoExtract Subcellular Proteome Extraction Kit (Calbiochem, Merck KGaA, Darmstadt, Germany) was used to separate soluble, insoluble and membrane protein fractions. The extraction was performed according to the manufacturer's instructions.

\section{ANO5 western blotting}

The membrane protein fractions were placed on ice and sonicated in water bath sonicator 3 x $1 \mathrm{~min}$, cooling on ice in between pulses. Alternatively, RIPA buffer, $\mathrm{pH}$ 8.0, supplemented with HALT/EDTA Protease Inhibitor Cocktail (100x) (Thermo Fisher Scientific, Waltham, MA, USA) was added to frozen muscle sections in precooled microcentrifuge tubes, lysed by vortexing for $10 \mathrm{sec}$, and sonicated as above. Laemmli sample buffer (1x) and beta-mercaptoethanol (10\%) were added, and the samples were incubated for $10 \mathrm{~min}$ at room temperature. Solution was centrifuged for $5 \mathrm{~min}, 16000 \mathrm{~g}$, and supernatant was used for SDS-PAGE and western blotting onto PVDF membranes using conventional methods. For COS-1 cells, $220 \mu 1$ RIPA with protease inhibitors was added to a single well on 6-well plate, and the cells were collected in a microcentrifuge tube using a cell scraper. The samples were processed by vortexing and sonication, as described above.

PVDF filters were detected using primary ANO5 mAb N421A/85 (UC Davis/NIH NeuroMab, Davis, CA, USA), raised against human ANO5 aa 1-299, at dilution 1:20 in TBST/5\% non-fat milk powder solution overnight at $+8^{\circ}$, with gentle agitation. Super Signal Femto (Pierce, Thermo Fisher Scientific) substrate at dilution 2:5 (in 
PBS) was used for ECL reaction, and the signal was detected with ChemiDoc reader (Bio-Rad Laboratories, CA, USA). Appropriate loading controls were used for different samples: myosin heavy chain (MyHC) band, stained with Coomassie Brilliant Blue, for total muscle extracts and insoluble fractions; GAPDH (ab8245, Abcam, Cambridge, UK) for COS-1 cells and muscle soluble fractions; pooled SERCA1/SERCA2 (clone VE121G9, Research Diagnostics Inc., NJ, USA and ab2817, Abcam, respectively) or DHPR (ab2862, Abcam) for muscle membrane fractions. V5 antibody (clone SV5-P-k, Invitrogen) was used to detect the V5-tagged constructs.

The ANO5, SERCA(1/2) and DHPR bands were quantitated using the ImageLab v5.0 software (BioRad) to obtain band volumes (integrated densities). Next, the ANO5/SERCA and ANO5/DHPR ratios were calculated for each sample. Average values of all control samples were calculated and normalized to 1 , in order to get the relative expression of ANO5 in each patient. 


\section{Results}

In transfected COS-1 cells, western blotting revealed a band migrating just above the $100 \mathrm{kD}$ marker, with both V5 and ANO5 N421A/85 antibodies, corresponding with the size of the expressed hANO5wt-V5 construct (109 kD) (Figure 1A). An additional $>200 \mathrm{kD}$ band was observed, likely representing ANO5 dimers. Three other ANO5 antibodies, one commercial and two custom-made, were tested as well, but they failed to recognize specifically the ANO5 protein in Western blotting (Supplemental Figure S2).

Next, muscle biopsy sections from normal controls and ANO5 patients were prepared into WB samples. A band of $\sim 100 \mathrm{kD}$ was observed in control muscle extracts, whereas this band seemed reduced to some extent in all patients (Figure 1B). No truncated ANO5 polypeptides were observed with the N-terminal ANO5 N421A/85 antibody. Several bands of different molecular weights were observed as well, but they were interpreted as unspecific, as they were present in all controls and patients tested. Notably, there were also unspecific bands just above and beneath of the fulllength ANO5, making reliable quantitation of specific bands impossible.

In order to study the ANO5 subcellular distribution, and to eliminate unspecific bands, we performed muscle tissue fractionation and analyzed the soluble (F1), membranous (F2) and insoluble (F4) fractions in controls and three ANO5 patients. In all controls and in patient Fin3 (c.2272C/c.2272C), a single 100 kD ANO5 band was clearly seen in the membrane fraction F2, but hardly detectable in patients Fin5 (c. 2272C>T/c.191dupA) and Ita3 (c.191dupA/c.191dupA) (Figure 1C). Notably, most unspecific bands were found in the soluble fraction F1. 
We then quantitated the ANO5 protein bands in membrane fractions of six controls and seven anoctaminopathy patients (Figure 2A), and determined the relative expression by calculating the ANO5/SERCA and ANO5/DHPR ratios (Figure 2B). The results were uniform with both membrane protein markers, showing that ANO5 was clearly decreased in all patients. The c.191dupA homozygous patient Ita3 showed only residual ANO5 expression, as expected; otherwise no clear correlation in expression could be seen with different mutations.

Because of the relatively selective involvement of different muscles in anoctaminopathy, we assessed the ANO5 protein expression level in a set of different control muscles. However, in the muscles tested (gastrocnemius, tibialis anterior, biceps femoris and semimembranosus), there were very small differences in the expression levels between individual specimens, but no marked differences between the different muscle groups (Supplemental Figure S3). A band of $\sim 100 \mathrm{kD}$ was consistently seen, and no sign of possible isoform variation.

Immunohistochemistry experiments were not successful in obtaining specific labeling using human muscle biopsies, probably due to too low affinity for the natural conformation of the protein (Supplemental Figure S4).

All the experiments were replicated 2-4 times, giving highly reproducible results. 


\section{Discussion}

Setting up a reliable method to detect endogenous ANO5 protein has proved to be very challenging. Previous attempts to determine ANO5 expression have been complicated by the high degree of unspecific signals with the ANO5 antibodies used, most of which have not identified the correct protein at all. For example, Xu et al. recently reported that two commercial ANO5 antibodies do not recognize ANO5 protein [13]. Possible reasons for ANO5 resistance for immunological detection may be its low immunogenicity and hydrophobic nature of eight transmembrane domains, making the extraction of ANO5 difficult.

Here, we used an SDS-PAGE sample preparation method, where membrane proteins are gently extracted using detergents and sonication in low temperature. With mAb clone N421A/85, COS-1 cells expressing the construct hANO5wt-V5 showed the correct band of $109 \mathrm{kD}$, which was absent in untransfected cells. In human total muscle lysates a $\sim 100 \mathrm{kD}$ band was observed, but also several unspecific bands, some of which very close in size to the ANO5 band. In order to confirm ANO5 membrane localization and monitor if it might change in patients, tissue fractionation was performed. ANO5 was found solely in the membrane fraction in all biopsies studied. No accumulation of ANO5 was seen in the insoluble fraction in any of the patients. By eliminating most unspecific bands, we were able to quantify ANO5 expression in relation to membrane protein markers SERCA(1/2) and DHPR. ANO5 protein was clearly reduced in all anoctaminopathy patients, regardless of the mutation. No truncated ANO5 protein fragments associated with frameshift mutations were detected. The mAb N421A/85 binding site may locate downstream of the c.191dupA mutation in exon 5, common in European population, and detection of such truncated 
product would therefore be impossible. However, if the nonsense mutation c.1261C $>\mathrm{T}$ in exon 13 would produce a truncated protein, it could have been recognized by the antibody. We conclude that these mutations likely cause nonsensemediated mRNA decay, and loss of ANO5 protein expression.

Hence, we show that the correct ANO5 protein is possible to detect with a specific methodology, and that it is expressed in human skeletal muscle as a single major isoform of $107 \mathrm{kD}$. Relatively sharp appearance of the band suggests no major high molecular weight covalent post-translational modifications, such as glycosylation, which is in agreement with the suggested localization of ANO5 in ER or intracellular membrane vesicles $[11,14,15]$ (based mostly on detection of tagged constructs in transfected cells).

In a recent biochemical study ANO5 was found to be an unstable protein, which undergoes constitutive proteasomal degradation [11], and the GDD mutation C356R was shown to further decrease ANO5 stability [11]. The myopathy-causing recessive ANO5 mutations are distributed throughout the gene. Based on the results described here, it seems likely that most, if not all mutations destabilize the protein, either by misfolding, compromising its processing in the ER, or affecting its correct incorporation into membranes, leading to more rapid degradation and decreased ANO5 levels. However, it cannot be ruled out that some mutations may primarily affect protein functionality. Different mutations leading to ANO5 instability and degradation could manifest as low genotype-phenotype correlation. Certainly, a wider spectrum of different ANO5 mutations needs to be analyzed to see which impact they have at the protein level. 
Direct detection of ANO5 by western blotting for diagnostic purposes and for determining pathogenicity of ANO5 mutations is now possible. Particularly, the large number of LGMD patients with both causative and elusive variants in the ANO5 gene would benefit from the protein analysis, making it a suitablesecond tier test after an NGS assay. We show that endogenous ANO5 protein is most reliably detected and quantitated by using isolated membrane protein fraction. The method described here provides a tool for research and further understanding of the ANO5 function. 
Acknowledgements: We thank Dr. Nobuyuki Kamata and Dr. Mitsuo Itakura for proving the hANO5-V5 construct, and Dr. A. Echaniz-Laguna for providing the Fra1 muscle biopsy. This study was supported by the Juselius, Erkko and Finnish Academy foundations (BU).

Author Contributions: A. Vihola: Design of the study, analysis and interpretation of the data, drafting the manuscript for intellectual content. H. Luque: Acquisition and interpretation of the data. M. Savarese: Design of the study, revising the manuscript for intellectual content. S. Penttilä, B. Eymard, B. Brais, T. Conte and K. Charton: Revising the manuscript for intellectual content. M. Lindfors and G. Tasca: Analysis and interpretation of the data. I. Richard: Interpretation of the data, revising the manuscript for intellectual content. B. Udd: Conceptualization of the study, revising the manuscript for intellectual content.

Conflict of Interest: The authors declare that they have no conflict of interest.

Ethical Approval: The biopsies used in this study were taken for diagnostic purpose and informed consent was obtained from all individual participants. The study has been approved by institutional review boards. Ethical approval (nr. 195/13/03/00/2011) has been given by the Coordinating Ethics Committee of The Hospital District of Helsinki and Uusimaa, Finland. 


\section{References}

1 Nigro V, Savarese M. Genetic basis of limb-girdle muscular dystrophies: The 2014 update. Acta Myol 2014; 33: 1-12

2 Bolduc V, Marlow G, Boycott KM, Saleki K, Inoue H, Kroon J, Itakura M, Robitaille Y, Parent L, Baas F, Mizuta K, Kamata N, Richard I, Linssen WH, Mahjneh I, de Visser M, Bashir R, Brais B. Recessive mutations in the putative calcium-activated chloride channel anoctamin 5 cause proximal LGMD2L and distal MMD3 muscular dystrophies. Am J Hum Genet 2010; 86: 213-221

3 Penttila S, Palmio J, Suominen T, Raheem O, Evila A, Muelas Gomez N, Tasca G, Waddell LB, Clarke NF, Barboi A, Hackman P, Udd B. Eight new mutations and the expanding phenotype variability in muscular dystrophy caused by ANO5. Neurology 2012; 78: 897-903

4 Sarkozy A, Hicks D, Hudson J, Laval SH, Barresi R, Hilton-Jones D, Deschauer M, Harris E, Rufibach L, Hwang E, Bashir R, Walter MC, Krause S, van den Bergh P, Illa I, PenissonBesnier I, De Waele L, Turnbull D, Guglieri M, Schrank B, Schoser B, Seeger J, Schreiber H, Glaser D, Eagle M, Bailey G, Walters R, Longman C, Norwood F, Winer J, Muntoni F, Hanna M, Roberts M, Bindoff LA, Brierley C, Cooper RG, Cottrell DA, Davies NP, Gibson A, Gorman GS, Hammans S, Jackson AP, Khan A, Lane R, McConville J, McEntagart M, AlMemar A, Nixon J, Panicker J, Parton M, Petty R, Price CJ, Rakowicz W, Ray P, Schapira AH, Swingler R, Turner C, Wagner KR, Maddison P, Shaw PJ, Straub V, Bushby K, Lochmuller H. ANO5 gene analysis in a large cohort of patients with anoctaminopathy: Confirmation of male prevalence and high occurrence of the common exon 5 gene mutation. Hum Mutat 2013; 34: 1111-1118 
5 Witting N, Duno M, Petri H, Krag T, Bundgaard H, Kober L, Vissing J. Anoctamin 5 muscular dystrophy in denmark: Prevalence, genotypes, phenotypes, cardiac findings, and muscle protein expression. J Neurol 2013; 260: 2084-2093

6 Savarese M, Di Fruscio G, Tasca G, Ruggiero L, Janssens S, De Bleecker J, Delpech M, Musumeci O, Toscano A, Angelini C, Sacconi S, Santoro L, Ricci E, Claes K, Politano L, Nigro V. Next generation sequencing on patients with LGMD and nonspecific myopathies: Findings associated with ANO5 mutations. Neuromuscul Disord 2015; 25: 533-541

7 Tsutsumi S, Kamata N, Vokes TJ, Maruoka Y, Nakakuki K, Enomoto S, Omura K, Amagasa T, Nagayama M, Saito-Ohara F, Inazawa J, Moritani M, Yamaoka T, Inoue H, Itakura M. The novel gene encoding a putative transmembrane protein is mutated in gnathodiaphyseal dysplasia (GDD). Am J Hum Genet 2004; 74: 1255-1261

8 Duong HA, Le KT, Soulema AL, Yueh RH, Scheuner MT, Holick MF, Christensen R, Tajima TL, Leung AM, Mallya SM. Gnathodiaphyseal dysplasia: Report of a family with a novel mutation of the ANO5 gene. Oral Surgery, Oral Medicine, Oral Pathology and Oral Radiology 2016; 121: e123-e128

9 Oh U, Jung J. Cellular functions of TMEM16/anoctamin. Pflugers Arch 2016; 468: 443-453

10 Griffin DA, Johnson RW, Whitlock JM, Pozsgai ER, Heller KN, Grose WE, Arnold WD, Sahenk Z, Hartzell HC, Rodino-Klapac LR. Defective membrane fusion and repair in Anoctamin5-deficient muscular dystrophy. Hum Mol Genet 2016; 25:1900-1911

11 Xu J, El Refaey M, Xu L, Zhao L, Gao Y, Floyd K, Karaze T, Janssen PM, Han R. Genetic disruption of Ano5 in mice does not recapitulate human ANO5-deficient muscular dystrophy. Skelet Muscle 2015; 5: 43; DOI 10.1186/s13395-015-0069-z 
12 Tsutsumi S, Inoue H, Sakamoto Y, Mizuta K, Kamata N, Itakura M. Molecular cloning and characterization of the murine gnathodiaphyseal dysplasia gene GDD1. Biochem Biophys Res Commun 2005; 331: 1099-1106

13 Mizuta K, Tsutsumi S, Inoue H, Sakamoto Y, Miyatake K, Miyawaki K, Noji S, Kamata N, Itakura M. Molecular characterization of GDD1/TMEM16E, the gene product responsible for autosomal dominant gnathodiaphyseal dysplasia. Biochem Biophys Res Commun 2007; 357: $126-132$

14 Tran TT, Tobiume K, Hirono C, Fujimoto S, Mizuta K, Kubozono K, Inoue H, Itakura M, Sugita M, Kamata N. TMEM16E (GDD1) exhibits protein instability and distinct characteristics in chloride channel/pore forming ability. J Cell Physiol 2014; 229: 181-190

15 Suzuki J, Fujii T, Imao T, Ishihara K, Kuba H, Nagata S. Calcium-dependent phospholipid scramblase activity of TMEM16 protein family members. J Biol Chem 2013; 288: 1330513316 
Figure legends

Figure 1. ANO5 western blotting of COS1 expressed ANO5-constructs and total muscle lysates

(A) Western blotting of hANO5wt-V5 constructs expressed in COS1 cells.

The western blots were detected with V5 mAb (left panel) or ANO5 mAb N421A/85 (right panel). With both antibodies, a monomer of $109 \mathrm{kD}$ hANO5wt-V5 is observed (black arrow), and a >200 band (white arrow), likely representing dimers. (B) ANO5 western blotting of total muscle lysate. A $~ 100 \mathrm{kD}$ ANO5 band (arrow) is observed in human healthy control muscles, and reduced in anoctaminopathy patients. However, several unspecific bands hinder quantitation of specific bands. Asterisk (*) indicates truncating mutations. Myosin heavy chain (MyHC) serves as a loading control. (C) Localization of ANO5 to muscle membrane fraction. ANO5 (black arrow) clearly segregates in the membranous fraction $\mathrm{F} 2$ in control muscle samples $(\mathrm{C} 1, \mathrm{C} 2, \mathrm{C} 3)$. The same distribution is seen in c. $2272 \mathrm{C}>\mathrm{T}$ homozygote Fin3, albeit with weaker signal. The Fin4 patient with c.191dupA/c.2272C > T shows severe decrease of ANO5, with no band detected. As expected, no ANO5 is seen in the Ita3 patient. ANO5 signal was not detected in soluble fraction F1 or insoluble fraction F4. Noteworthy, most unspecific bands (white arrows) are in the soluble fraction, and one of them very close to the $\sim 100 \mathrm{kD}$ ANO5 band. 


\section{Figure 2. ANO5 western blotting of muscle membrane fractions}

(A) Detection of ANO5 in the muscle biopsy membrane fractions (F2) reveals a single $\sim 100 \mathrm{kD}$ band, which is clearly reduced in all anoctaminopathy patients $(\mathrm{n}=7)$. Asterisk (*) indicates truncating mutations. Membrane proteins SERCA (pooled SERCA1 and SERCA2) and DHPR are used as specific loading controls. (B) Graphs illustrating the ANO5 expression in individual patients. Bands shown in Figure 2A were quantitated, and ANO5/SERCA and ANO5/DHPR ratios were calculated. Controls $(n=6)$ were combined, and their average value was normalized to 1 (column 1). The expression of ANO5 in all patient samples (columns 2-8) was clearly decreased, being lowest in Fin5 (c.191dupA/c.2272C>T) and Ita3 (c.191dupA/ c.191dupA). The experiment was performed in duplicate, with similar results. ANO5/SERCA, controls: min value $=0.606 ;$ max value $=2,021 ;$ average $=1,000 ;$ STDEV = 0,533; ANO5/SERCA, patients: $\min$ value $=0,019 ;$ max value: 0,297; average $=0,123 ;$ STDEV $=0,096$. ANO5/DHPR, controls: min value $=0,661 ; \max$ value $=1,287 ;$ average $=1,000 ;$ STDEV $=0,249 ;$ ANO/DHPR, patients: min value $=$ 0,$016 ;$ max value $=0,289 ;$ average $=0,135 ;$ STDEV $=0,106$ 
Table 1.

\begin{tabular}{|c|c|c|c|c|c|c|}
\hline $\begin{array}{l}\text { Patient } \\
\text { ID }\end{array}$ & $\mathbf{M} / \mathbf{F}$ & Nucleotide change & $\begin{array}{l}\text { Amino acid } \\
\text { change }\end{array}$ & Muscle & Phenotype & Reference \\
\hline Fin1 & M & $\begin{array}{l}{[\mathrm{c} .2101 \mathrm{~A}>\mathrm{G}]} \\
{[\text { c. } 2272 \mathrm{C}>\mathrm{T}]}\end{array}$ & $\begin{array}{l}\text { p.N701D; } \\
\text { p.R758C }\end{array}$ & $\begin{array}{l}\text { Vastus } \\
\text { lateralis }\end{array}$ & $\begin{array}{l}\text { Proximal UL, LL weakness; onset at age } \\
\text { 35; CK 1000-3000; EMG myopathy }\end{array}$ & $\begin{array}{l}\text { Penttilä et. al } \\
2012 \text { [3] }\end{array}$ \\
\hline Fin2 & M & $\begin{array}{l}{[\text { c. } 2272 \mathrm{C}>\mathrm{T}] ;} \\
{\left[\text { c. } 2311 \_2312 \mathrm{delCA}\right]}\end{array}$ & $\begin{array}{l}\text { p.R758C; } \\
\text { p.Q771Afs*8 }\end{array}$ & NA & $\begin{array}{l}\text { LGMD; onset at age } 20 ; \text { CK 5000-14 000; } \\
\text { EMG myopathy }\end{array}$ & $\begin{array}{l}\text { Penttilä et. al } \\
2012 \text { [3] }\end{array}$ \\
\hline Fin3 & $\mathrm{M}$ & $\begin{array}{l}\text { [c. } 2272 \mathrm{C}>\mathrm{T}] \\
{[\text { c. } 2272 \mathrm{C}>\mathrm{T}]}\end{array}$ & $\begin{array}{l}\text { p.R758C; } \\
\text { p.R758C }\end{array}$ & NA & $\begin{array}{l}\text { LGMD; onset at age 50; CK 1400-6000; } \\
\text { EMG myopathy }\end{array}$ & $\begin{array}{l}\text { Penttilä et. al } \\
2012[3]\end{array}$ \\
\hline Fin4 & M & $\begin{array}{l}\text { [c. } 2272 \mathrm{C}>\mathrm{T}] \\
{[\text { c. } 2272 \mathrm{C}>\mathrm{T}]}\end{array}$ & $\begin{array}{l}\text { p.R758C; } \\
\text { p.R758C }\end{array}$ & $\begin{array}{l}\text { Tibialis } \\
\text { anterior }\end{array}$ & LGMD; onset at age 50; CK 4000 & - \\
\hline Fin5 & $\mathrm{F}$ & $\begin{array}{l}\text { [c.191dupA]; } \\
{[\text { c. } 2272 \mathrm{C}>\mathrm{T}]}\end{array}$ & $\begin{array}{l}\text { p.N64Kfs*15; } \\
\text { p.R758C }\end{array}$ & $\begin{array}{l}\text { Vastus } \\
\text { lateralis }\end{array}$ & $\begin{array}{l}\text { HyperCKemia, no weakness; onset at age } \\
40 ; \text { CK 1000-9000; EMG normal }\end{array}$ & $\begin{array}{l}\text { Penttilä et. al } \\
2012[3]\end{array}$ \\
\hline Fin6 $^{\mathbf{a}}$ & $\mathrm{F}$ & {$[$ r.1656_2109del]; } & p.Y552*; & $\begin{array}{l}\text { Vastus } \\
\text { lateralis }\end{array}$ & $\begin{array}{l}\text { Mild proximal UL, LL weakness; onset at } \\
\text { age 70; CK 1500-4000; EMG myopathy }\end{array}$ & - \\
\hline Fra1 & M & $\begin{array}{l}\text { [c.191dupA]; } \\
\text { [c.191dupA] }\end{array}$ & $\begin{array}{l}\text { p.N64Kfs*15; } \\
\text { p.N64Kfs*15 }\end{array}$ & NA & $\begin{array}{l}\text { LGMD; onset at age 50; CK } 2000-4000 \text {; } \\
\text { dystrophic pattern on the biopsy }\end{array}$ & - \\
\hline Ita1 & M & $\begin{array}{l}\text { [c.191dupA]; } \\
{[\text { c.1261C }>\mathrm{T}]}\end{array}$ & $\begin{array}{l}\text { p.N64Kfs*15; } \\
\text { p.Q421* }\end{array}$ & Quadriceps & $\begin{array}{l}\text { LGMD; onset age 50; asymmetric proximal } \\
\text { UL and LL weakness; CK 2200-3000; } \\
\text { EMG myopathy }\end{array}$ & $\begin{array}{l}\text { Savarese et } \\
\text { al. } 2015 \text { [6] }\end{array}$ \\
\hline Ita2 & $\mathrm{F}$ & $\begin{array}{l}\text { [c.1502delT]; } \\
{[\text { c. } 1899-4 \mathrm{~A}>\mathrm{G}]}\end{array}$ & $\begin{array}{l}\text { p.F507Sfs*6; } \\
\text { predicted to affect } \\
\text { splicing }\end{array}$ & Quadriceps & $\begin{array}{l}\text { LGMD; onset age 50, asymmetric proximal } \\
\text { UL and LL weakness; CK 3500; EMG } \\
\text { myopathy }\end{array}$ & $\begin{array}{l}\text { Penttilä et. al } \\
2012[3]\end{array}$ \\
\hline Ita3 & & $\begin{array}{l}\text { [c.191dup]; } \\
\text { [c.191dup] }\end{array}$ & $\begin{array}{l}\text { p.N64Kfs*15; } \\
\text { p.N64Kfs*15 }\end{array}$ & Deltoid & $\begin{array}{l}\text { LGMD; onset age 40; asymmetric proximal } \\
\text { UL and LL weakness; CK } 1200\end{array}$ & - \\
\hline
\end{tabular}

Abbreviations: $\mathrm{UL}=$ upper limb; $\mathrm{LL}=$ lower limb; $\mathrm{NA}=$ not available

${ }^{a}$ One ANO5 anomaly at mRNA level only; disease control 
Table 2.

\begin{tabular}{|c|l|}
\hline Control ID & Muscle(s) \\
\hline C1 & Deltoideus \\
\hline C2 & $\begin{array}{l}\text { Biceps femoris, } \\
\text { Semimembranosus, } \\
\text { Sartorius, } \\
\text { Gracilis }\end{array}$ \\
\hline & $\begin{array}{l}\text { Biceps femoris, } \\
\text { Sartorius }\end{array}$ \\
\hline C3 & Gastrocnemius \\
\hline C4 & Gastrocnemius \\
\hline C5 & Gastrocnemius \\
\hline C6 & Gastrocnemius \\
\hline C8 & Gastrocnemius \\
\hline C9 & Tibialis anterior \\
\hline C10 & Tibialis anterior \\
\hline C11 & Tibialis anterior \\
\hline
\end{tabular}


A

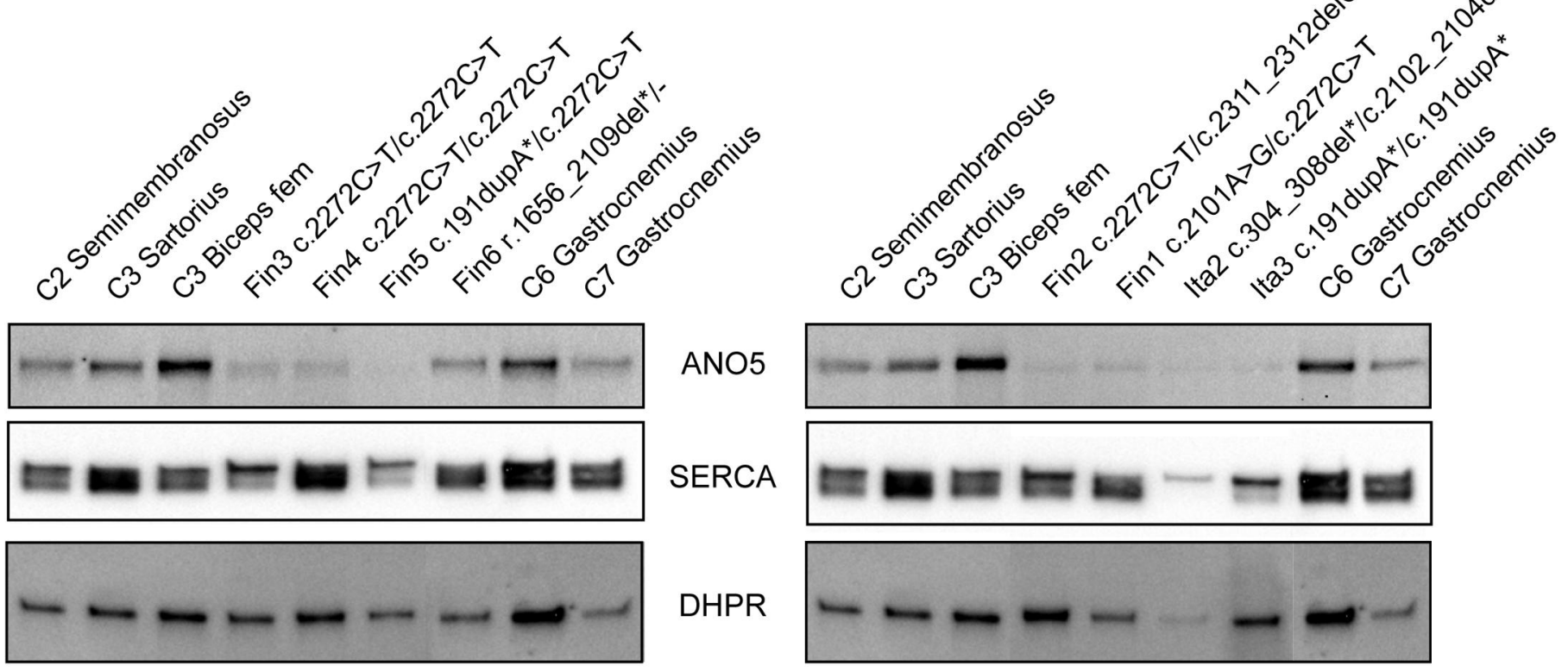

F2 membrane fractions

F2 membrane fractions

B

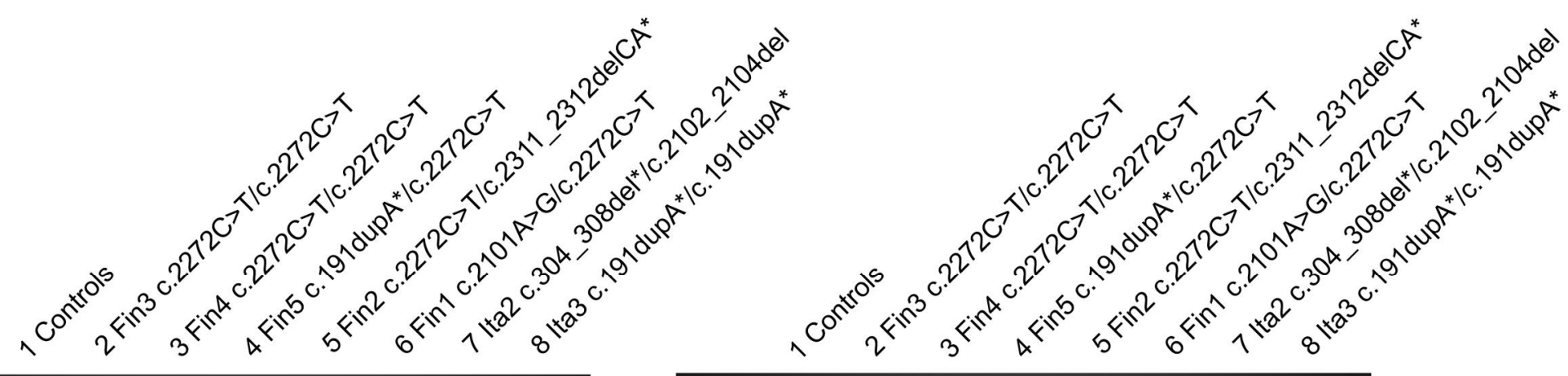

\section{ANO5/SERCA}
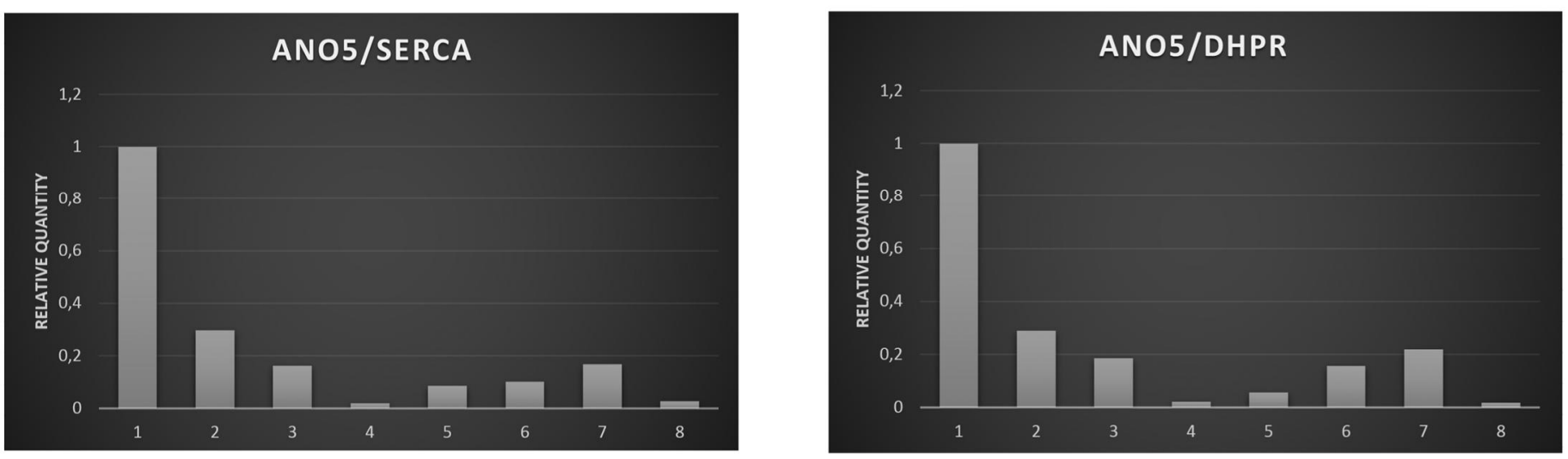


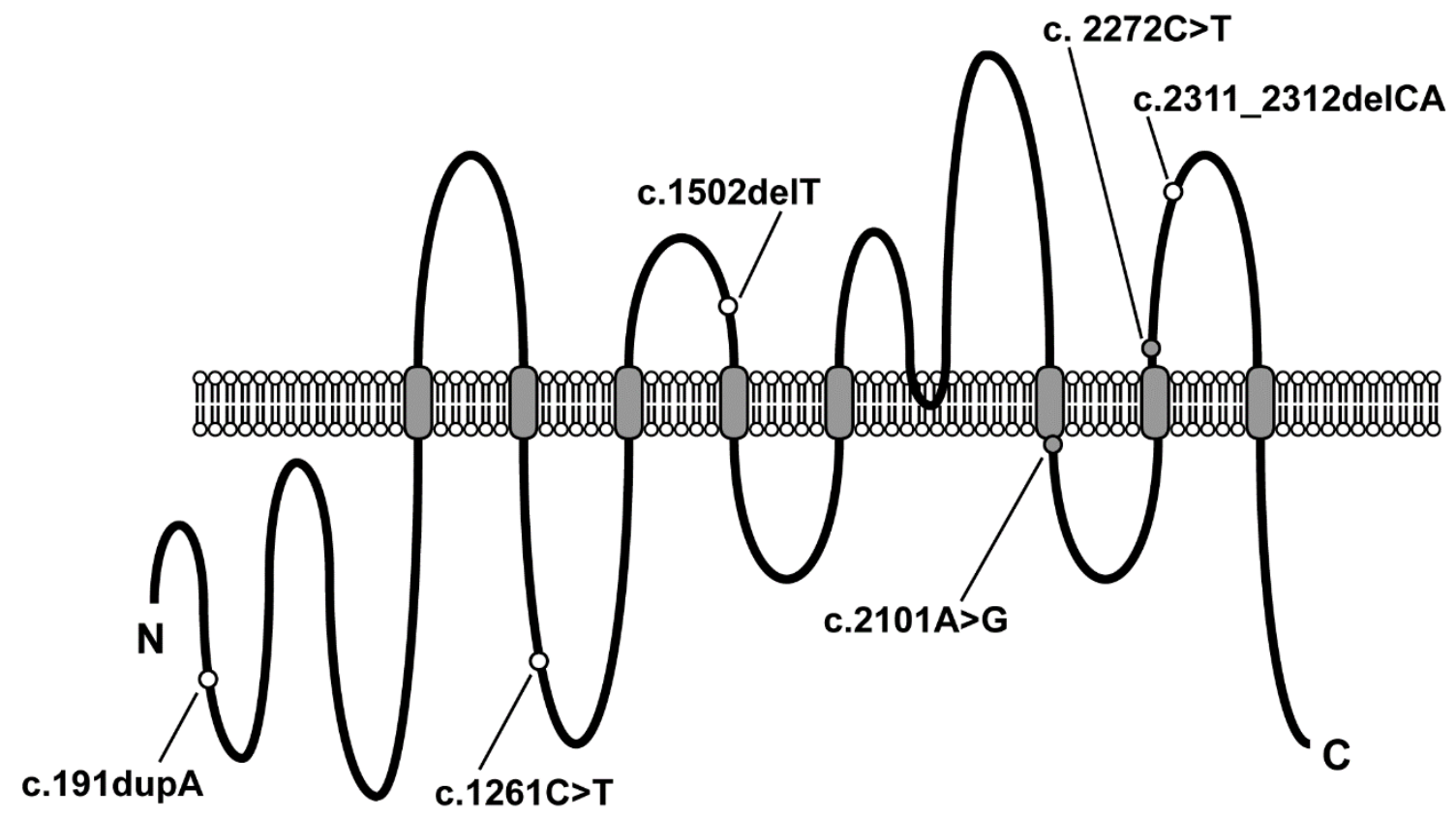

Supplemental Figure 1. Schematic Presentation of the ANO5 Protein.

Locations of the ANO5 mutations included in this study are shown in the schematic picture. Empty circle = truncating mutation; grey circle = missense mutation . 

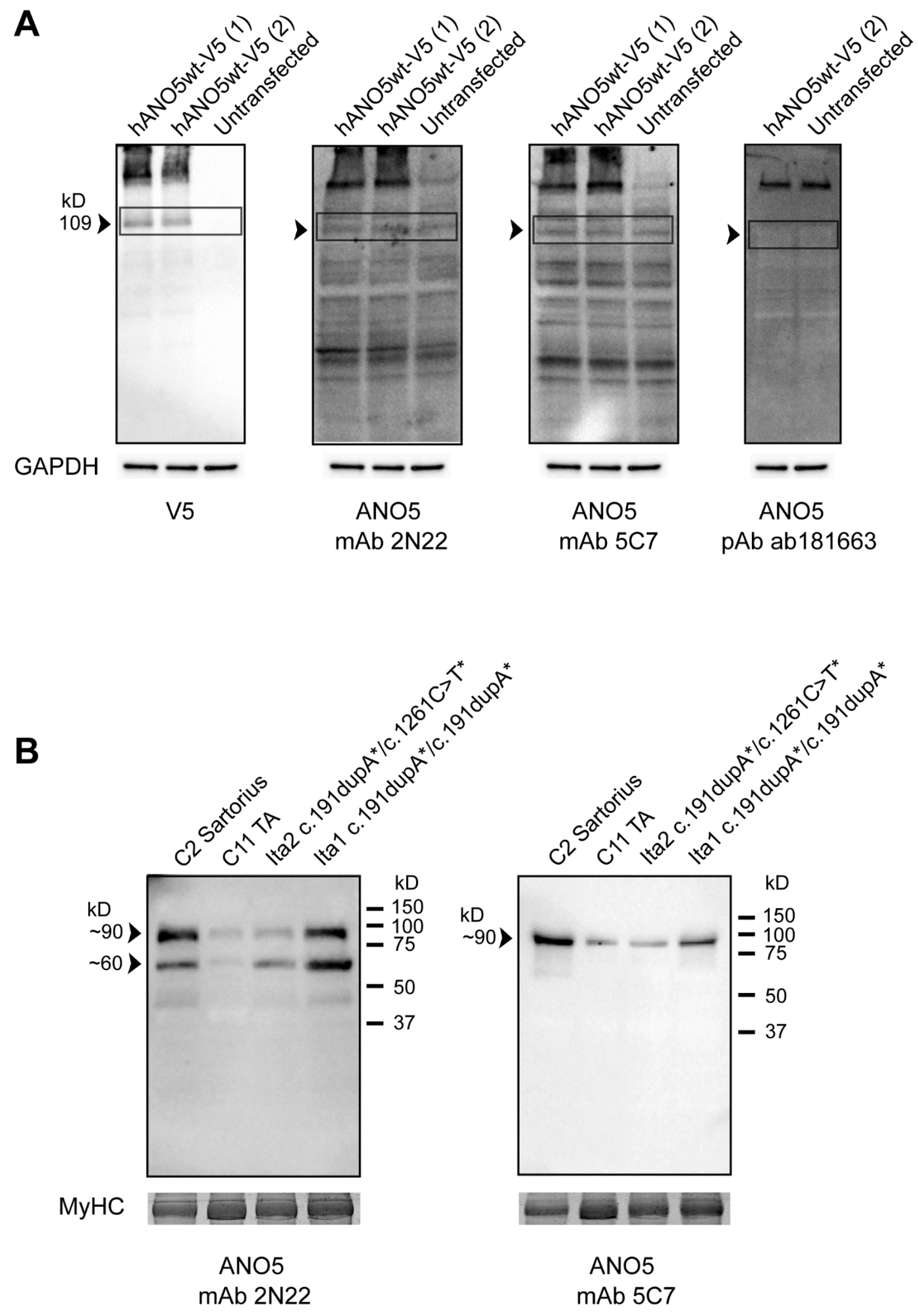


\section{Supplemental Figure S2. Characterization of Other ANO5 Antibodies.}

The specificity of three additional ANO5 antibodies was investigated: monoclonal mouse antibody (mAb) 2N22 was raised against the sequence SEKLYSRWEQ, human ANO5 aa 648-657, in the extracellular domain 4 , and $\mathrm{mAb} 5 \mathrm{C} 7$ was raised against $\mathrm{N}$-terminal sequence aa 1-90:

MGDPDLLEVLAEEGEKVNKHIDYSFQMSEQSLSSRETSFLINEETMPAKRFNLFLRRRLMFQ KNQQSKDSIFFRDGIRQIDFVLSYVDDV). The commercial rabbit polyclonal ab181663 (Abcam) was generated against an undefined sequence within ANO5 $\mathrm{N}$-terminus. Noteworthy, the mAb N421A/85 was also generated by using the N-terminal intracellular domain aa 1-299 as immunogen.

A) In COS- 1 cells transfected with hANO5WT-V5, the construct monomer of $109 \mathrm{kD}$ is observed (black arrow), and also a higher molecular weight dimer band (white arrow), when detected with V5 tag antibody. With antibodies 2N22, 5C7 and ab181663, the construct monomer is not detected, but instead with $\mathrm{mAbs} 2 \mathrm{~N} 22$ and $5 \mathrm{C} 7$, an unspecific band of similar size in both transfected and untransfected cells is seen (boxed area). In addition, the 2N22 and $5 \mathrm{C} 7$ blots show a band of the size of construct dimer in transfected cells (white arrows). However, this band is interpreted as unspecific, as the antibodies fail to recognize the monomeric construct. The erroneous labeling is caused by unspecific binding of either primary or secondary antibody to the large mass of overexpressed protein, in the absence of specific antibody-antigen interaction.

B) When human muscle samples are detected with mAbs 2N22 and 5C7, no ANO5 band of $107 \mathrm{kD}$ is detected. Instead, unspecific bands of $\sim 90 \mathrm{kD}$ and $\sim 60 \mathrm{kD}$ are observed similarly in controls and patients Fra1 and Ita1 with truncating ANO5 mutations in both alleles. 

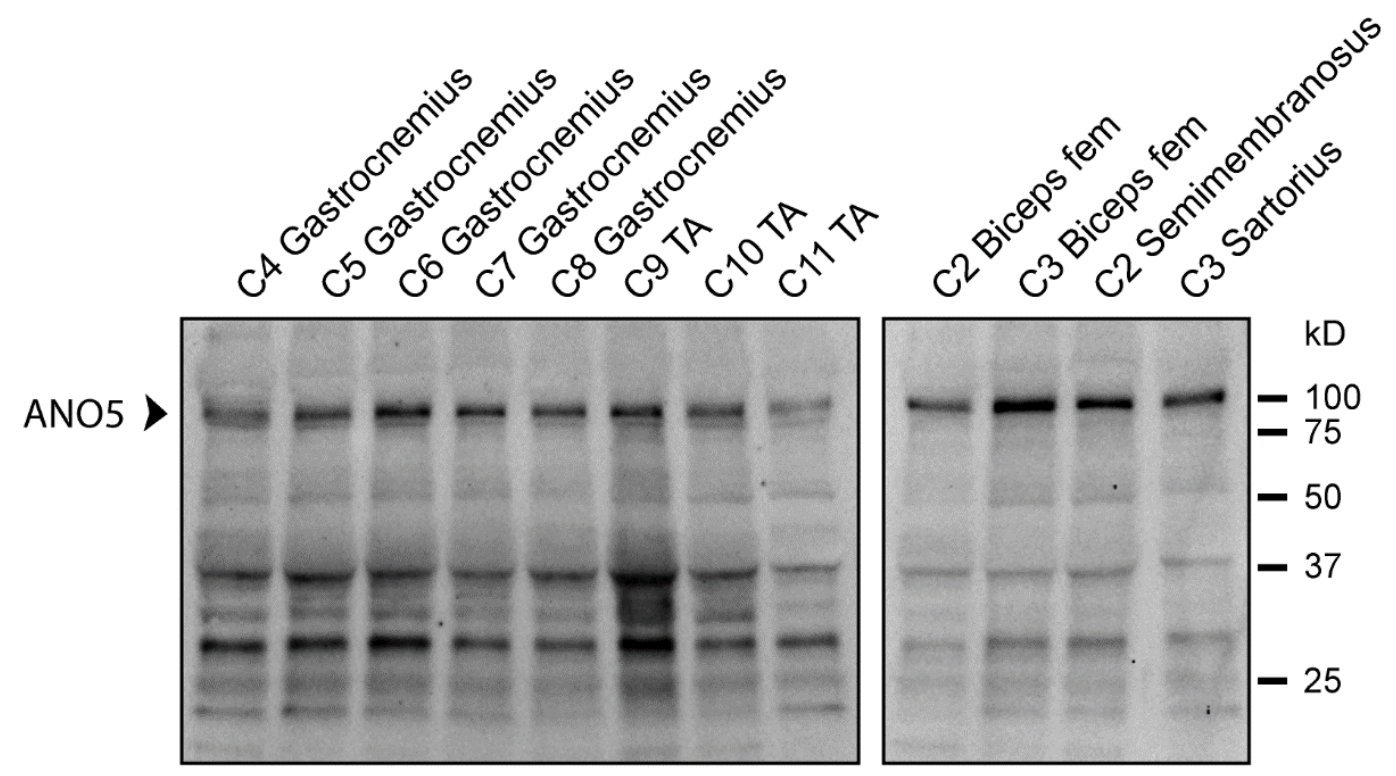

$\mathrm{MyHC}$

\section{Supplemental Figure S3. ANO5 Expression in Different Normal Control Muscles.}

One ANO5 band of $\sim 100 \mathrm{kD}$ (arrow) is observed in all control samples, indicating that ANO5 is expressed as a single isoform in all muscles analyzed: gastrocnemius, tibialis anterior, biceps femoris, semimembranosus and sartorius. Moderately different levels of expression are seen, but there are no systematic differences between the tested muscles to account for the differences in muscle involvement in LGMD2L. 
A

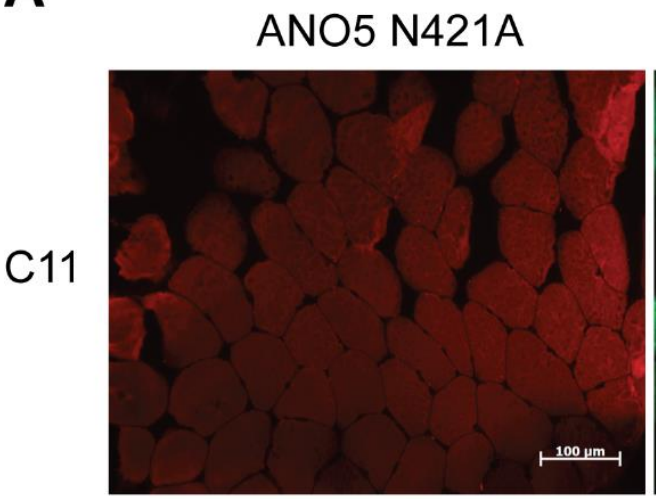

Calsequestrin

Merge
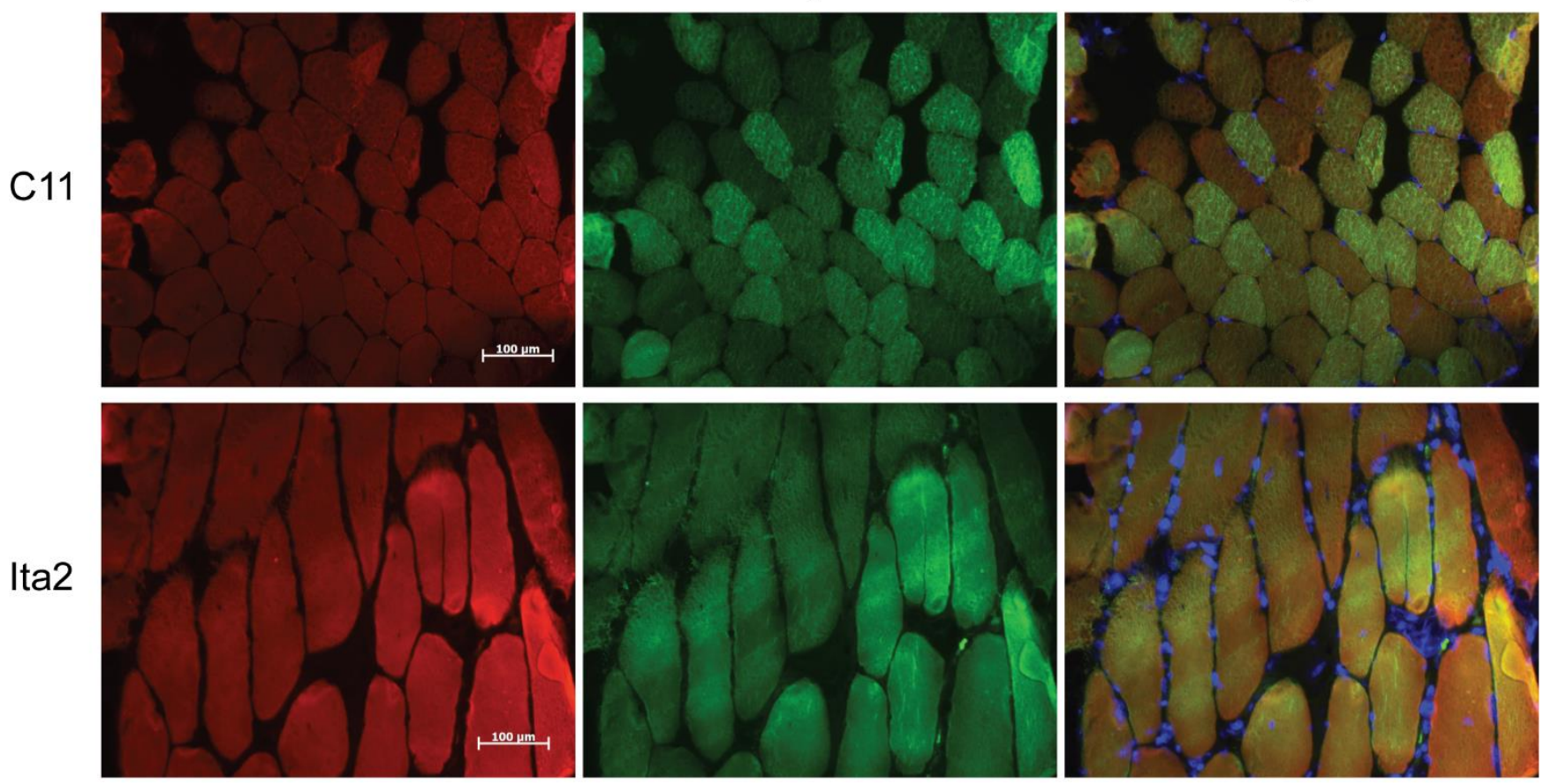

B

ANO5 ab181663

C11

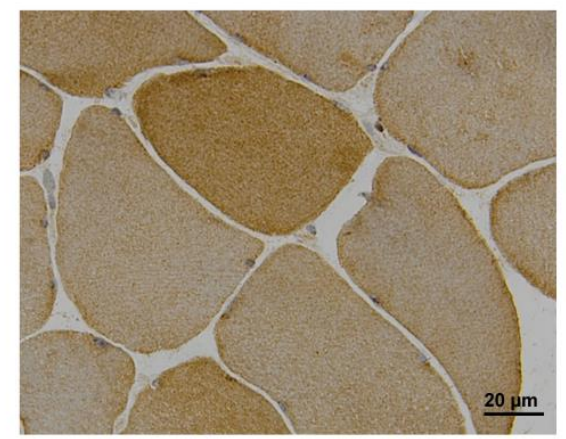

Ita2

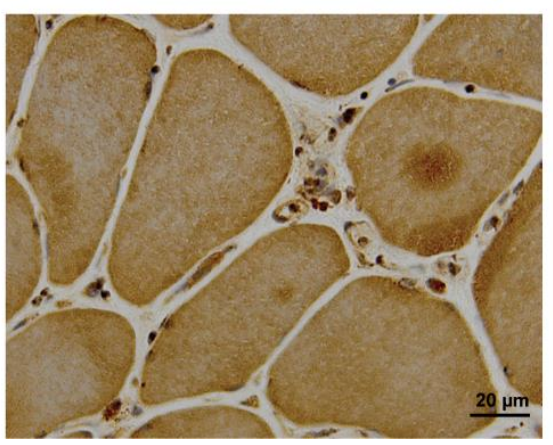




\section{Supplemental Figure S4. ANO5 Immunohistochemistry.}

Frozen muscle sections $(8 \mu \mathrm{m})$ were prepared on slides, and treated in different ways in order to obtain ANO5-specific labelling. The slides were fixed either with $4 \%$ paraformaldehyde (PFA) for $10 \mathrm{~min}$, formalin for $15 \mathrm{~min}$, ice-cold acetone for $10 \mathrm{~min}$, ice-cold methanol for 10 min, or were stained without fixing. A subset of the PFA/formalin fixed slides were subjected to antigen retrieval with EDTA buffer $\mathrm{pH}$ 8.0, or citrate buffer, $\mathrm{pH}$ 6.0: the slides in retrieval buffer solution in plastic jars were brought to boiling temperature for $5 \mathrm{~min}$ in a microwave oven, and let cool down in the buffer solution for 20-30 min prior to washing with PBS. The slides were immunostained with ANO5 mAb N421 A/85 or pAb ab181663, using either manual immunofluorescent detection, primary antibody incubation overnight at $+8^{\circ} \mathrm{C}$, or automated DAB-immunohistochemistry with HRP-conjugated secondary antibodies (Ventana Benchmark, Ventana Medical Systems, Tucson, AZ). However, all the immunohistochemical experiments failed to show ANO5-specific labelling, as positive and negative controls were identical on examination. Examples are shown in figures $(A)$ and $(B)$.

A) Immunofluorescent analysis using PFA-fixation and ANO5 mAb N421A/85. The sections were pretreated with $1 \%$ SDS prior to primary Ab incubation, in order to achieve protein denaturation and epitope exposure. The samples showed diffuse cytoplasmic labeling with ANO5 (red), which turned out to be unspecific as it was similar in controls and patient Ita1 with two truncating ANO5 mutations. Calsequestrin (green) was used as a sarcoplasmic reticulum marker. Scale bar $100 \mu \mathrm{m}$.

B) Automated DAB-immunohistochemistry with pAb ab181663 (dilution 1:50, no fix, amplification) similarly showed cytoplasmic labeling (brown), which was not reduced in patient Ita1, and hence unspecific. Scale bar $20 \mu \mathrm{m}$. 